\title{
Perancangan User Experience Aplikasi Pengajuan E-KTP Menggunakan Metode UCD Pada Kelurahan Tanah Baru
}

\author{
Sarfina Luthfiyah Ramadhan*1, Iskandar Fitri' ${ }^{2}$, Albaar Rubhasy ${ }^{3}$ \\ ${ }^{1,2,3}$ Informatika, Fakultas Teknologi Komunikasi dan Informatika, Universitas Nasional \\ e-mail: *1 sarfinaramadhan12@gmail.com, ${ }^{2}$ tektel2001@yahoo.com, \\ 3albaar.rubhasy@civitas.unas.ac.id
}

\begin{abstract}
Abstrak
KTP elektronik adalah dokumen publik yang memiliki sistem pengamanan atau pengendalian dalam hal pengelolaan dan teknologi informasi berbasis data nasional. Di era digital ini, Kantor Kelurahan Tanah Baru masih melakukan pelayanan pembuatan KTP secara manual. Hal tersebut dinilai kurang efisien karena pemohon harus mengantre dan menunggu lama sampai proses pembuatan KTP selesai. Kurangnya tenaga pekerja membuat proses pembuatan KTP memakan waktu yang cukup lama. Hasil dari penelitian ini adalah menerapkan metode user centered design pada sistem aplikasi pembuatan KTP Elektronik. Keuntungan dari metode UCD adalah untuk membangun sebuah sistem aplikasi pengajuan pembuatan E-KTP dengan tingkat efisiensi yang tinggi dan mudah digunakan karena pada prosesnya metode UCD melibatkan pengguna dalam keseluruhan proses perancangan.
\end{abstract}

Kata kunci-Sistem Informasi, User Experience, User Centered Design.

\begin{abstract}
Electronic KTP is a public document that has a security or control system in terms of management and information technology-based on national data. In this digital era, the Tanah Baru Urban Village Office is still providing services for making ID cards manually. This is considered inefficient because applicants have to queue and wait a long time until the KTP process is complete. Lack of labor force made the process of making a KTP take quite a long time. The result of this research is to apply the user-centered design method to the application system for making electronic ID cards. The advantage of the UCD method is to build an application system for making E-KTP applications with a high level of efficiency and is easy to use because the UCD method involves the user in the entire design process.
\end{abstract}

Keywords - Information System, User Experience, User Centered Design

\section{PENDAHULUAN}

$P$ erkembangan ilmu pengetahuan dan teknologi informasi saat ini sangat berpengaruh terhadap perkembangan hampir di semua aspek kehidupan [1]. Peranan teknologi sangat diperlukan untuk mempermudah pekerjaan agar lebih cepat dan tepat [2]. Salah satu fungsi komputer adalah untuk mengolah data menjadi informasi yang diperlukan oleh pengguna, dimana informasi akan cepat diterima melalui sistem informasi. Kantor kelurahan merupakan salah satu pihak yang memanfaatkan kemudahan teknologi dan informasi untuk mengolah data. 
Kelurahan Tanah Baru saat ini belum memiliki sebuah sistem informasi yang dapat memberikan informasi kepada masyarakat mengenai alur dan proses pembuatan KTP Elektronik. Kelurahan Tanah Baru memiliki jumlah penduduk yang banyak, oleh karena itu pengajuan permohonan pembuatan KTP Elektronik di Kantor Kelurahan selalu ramai. Jumlah tenaga kerja yang sedikit berimbas pada lamanya proses pembuatan KTP Elektronik.

Berdasarkan penjelasan di atas, untuk membantu mempercepat proses pengajuan untuk pembuatan KTP Elektronik, maka penulis membuat sebuah rancangan aplikasi mobile sistem informasi pengajuan pembuatan KTP Elektronik. Aplikasi mobile menjadi produk yang banyak digunakan di perangkat seluler [3]. Maka dari itu, merupakan hal penting untuk memastikan bahwa aplikasi yang dibangun dapat selalu memenuhi kebutuhan pengguna. Untuk dapat memenuhi kebutuhan pengguna, perlu diperhatikan beberapa aspek seperti kepuasan pengguna dari perspektif fungsionalitas dan kemudahan dalam penggunaan, efisiensi dan kemudahan dalam mempelajari aplikasi. Memahami kebutuhan pengguna dari perspektif apa yang mereka lakukan dan apa yang mereka butuhkan selain pertimbangan emosional adalah sesuatu yang harus dipertimbangkan dalam konsep perancangan sistem aplikasi dengan user experience yang baik. [4].

Pengertian user experience dapat berbeda secara istilah dan konteks. Secara umum, user experience bertujuan untuk meningkatkan interaksi antara sistem dan pengguna [5]. Menurut organisasi standar internasional, user experience adalah persepsi dan tanggapan individu yang diperoleh dari penggunaan produk, sistem, atau layanan [6]. Secara umum, User experience dipahami sebagai sesuatu yang dinamis, dimana kondisi internal dan emosional seorang individu dapat berubah pada saat berinteraksi dengan produk atau setelah selesai menggunakan produk tersebut [7].

Pada bidang Human Computer Interaction, studi awal berfokus pada kegunaan yang menekankan kinerja yang menitikberatkan pada performa, pencapaian yang efektif dan sesuai dengan sasaran. Saat ini, pendekatan user experience telah mencapai aspek kognitif dan emosional yang lebih luas dan rumit yang dilihat dari pengalaman manusia [8]. Perancangan aplikasi berbasis mobile ini dikembangkan dengan menggunakan metode UCD karena mempertimbangkan target pengguna yang sudah jelas. Menurut penelitian yang dilakukan oleh Bayu Priyatna UCD merupakan metode baru dalam pengembangan sistem. UCD adalah metode baru dalam pengembangan sistem aplikasi. UCD adalah metode yang banyak digunakan untuk menggambarkan rancangan aplikasi. Konsep UCD menempatkan pengguna sebagai pusat dari proses sistem yang sedang dikembangkan. Tujuan lingkungan sistem secara keseluruhan didasarkan pada pengalaman pengguna [9].

Penelitian lain dilakukan oleh Yatana Saputri dkk yang melakukan pengujian dengan metode usability testing. Penelitian ini menerapkan metode UCD pada pembangunan website ECommerce. Pada penelitian ini dilakukan tahap penyebaran kuesioner agar mengetahui kebutuhan pengguna. Setelah data diperoleh, maka dibangun sebuah perancangan antarmuka sistem sesuai dengan data kebutuhan pengguna yang sudah didapat. Lalu dilakukan testing menggunakan metode pengujian usability testing dengan menerapkan perhitungan skala linkert. Pada penelitian tersebut, usability untuk setiap iterasi menghasilkan nilai yang berbeda. Jika tahap iterasi semakin tinggi untuk dilakukan maka nilai usability yang didapat akan semakin tinggi [10]. 


\section{METODE PENELITIAN}

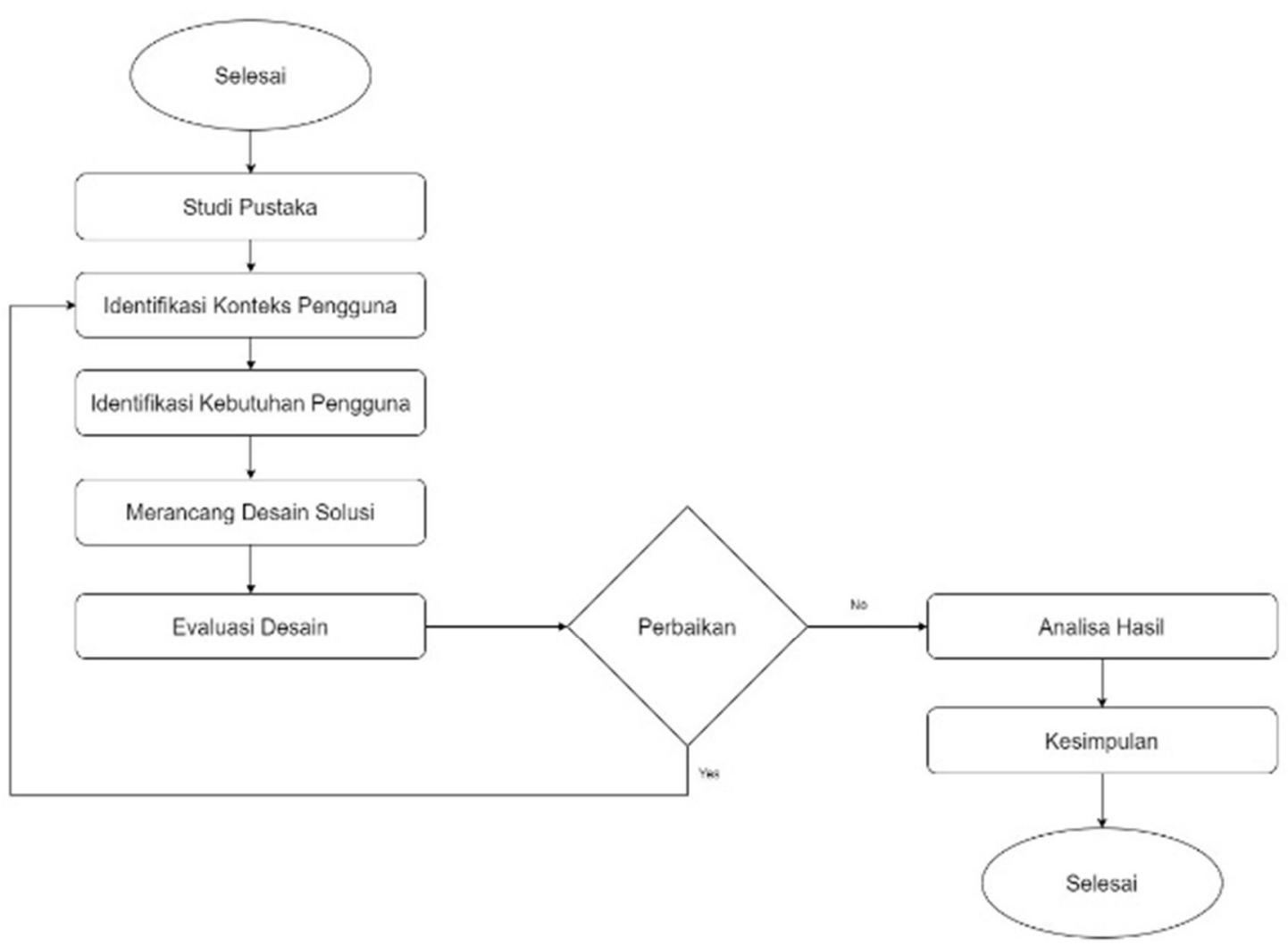

Gambar 1. Metodologi Penelitian

User Centered Design adalah sebuah metode perancangan yang memusatkan pengguna dalam pengembangan rancangan sistem aplikasi. Rancangan aplikasi yang dikembangkan menggunakan metode UCD berfokus pada kebutuhan pengguna terhadap aplikasi. Dalam proses interaksi antara pengguna dengan sistem informasi pengajuan E-KTP harus mendapatkan kenyamanan seperti pada saat menggunakan sistem lain, sehingga pengguna tidak perlu mengubah perilakunya.

Tahapan penelitian yang akan dilakukan memiliki alur yang ada pada Gambar 1, dimana alur utama dari penelitian adalah dengan mengimplementasikan metode user centered design pada proses penelitian. Penelitian dimulai dengan melakukan studi pustaka. Pada tahapan ini, penelitian dilakukan dengan mencari sumber-sumber data dan informasi mengenai proses penelitian. Sumber informasi yang digunakan terdapat beberapa panduan penyelesaian terhadap masalah yang sedang diteliti. Contoh informasi yang digunakan adalah informasi mengenai perancangan user interface dan user experience serta informasi penerapan metode user centered design.

Pada tahapan selanjutnya, yaitu tahapan perancangan dengan metode UCD. Tahapan ini dimulai dengan analisis konteks pengguna yang terdiri dari pembuatan persona pengguna dan penyebaran kuesioner kebutuhan yang ditujukan untuk mengumpulkan data dan informasi calon pengguna. Lalu pada tahap identifikasi kebutuhan pengguna merupakan bertujuan untuk mendapatkan informasi pengguna dengan cara melakukan wawancara dan penyebaran kuesioner kepada calon pengguna. 
Selanjutnya pada tahapan perancangan desain solusi merupakan implementasi dari kebutuhan yang ada. Pada tahap ini, dibuatkan rancangan wireframe, userflow, serta prototype yang akan dapat diujikan kepada calon pengguna. Lalu tahapan terakhir dalam metode UCD adalah evaluasi desain solusi, dilakukan dengan metode pengujian usability dan metode system usability scale untuk mengetahui tingkat efisiensi, efektifitas, dan kepuasan pengguna dengan desain solusi yang sudah dirancang.

Tahap selanjutnya adalah analisis hasil dari pengujian yang telah dilakukan. Tahapan ini bertujuan untuk mengetahui hasil, serta kekurangan dan kelebihan dari penelitian yang sudah dilakukan. Kemudian pada tahapan terakhir dari penelitian adalah kesimpulan. Tahapan ini bertujuan untuk menjawab masalah penelitian sesuai dengan hasil penelitian yang sudah dilakukan.

\section{HASIL DAN PEMBAHASAN}

\subsection{Identifikasi Konteks Pengguna}

Tahapan utama dalam metode User Centered Design dapat dilihat pada gambar 2.

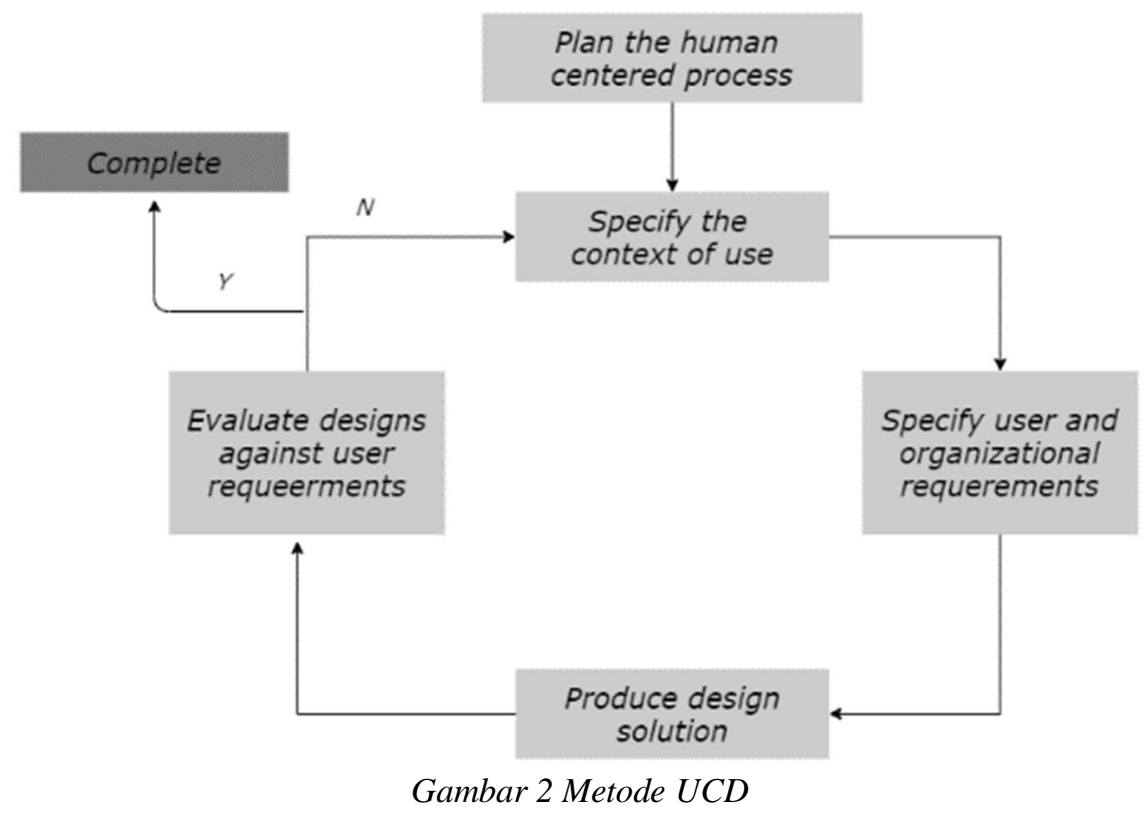

\section{Karakteristik Pengguna}

Dari hasil analisis yang sudah dilakukan dengan mengumpulkan data dan melakukan wawancara. Pengguna aplikasi sistem informasi pengajuan E-KTP ini adalah masyarakat Indonesia dengan rentang umur 15 sampai 17 tahun dan belum memiliki E-KTP.

Karakteristik pengguna aplikasi sistem informasi pengajuan E-KTP adalah:

A. Semua kalangan masyarakat Indonesia dengan rentang umur 15-17 tahun.

B. Pengguna belum pernah mengajukan pembuatan E-KTP.

C. Pengguna dapat menggunakan perangkat smartphone.

D. Pengguna aplikasi tidak memerlukan minimal pendidikan. 


\subsubsection{Identifikasi Tujuan dan Tugas Pengguna}

Tujuan dari perancangan aplikasi ini adalah sebagai media penyampaian informasi agar masyarakat dapat mengajukan permohonan pembuatan E-KTP dengan cepat dan mudah. Pengguna diharapkan dapat melakukan proses pengajuan dengan cepat dan dapat dengan mudah memantau proses pengajuan yang sudah dilakukan. Pengguna mengharapkan aplikasi yang sederhana dan mudah digunakan. Informasi mengenai aktivitas pengguna pada saat menggunakan aplikasi didapatkan dari hasil pengumpulan informasi dari penelitian sebelumnya. Hasil identifikasi tugas pengguna dapat dilihat pada Tabel 1.

Tabel 1. Tugas Pengguna

\begin{tabular}{|c|l|}
\hline Kode Tugas & \multicolumn{1}{|c|}{ Nama Tugas } \\
\hline T1 & Pengguna melakukan registrasi akun \\
\hline T2 & Pengguna melakukan login dengan akun \\
\hline T3 & Pengguna dapat melihat persyaratan pengajuan \\
\hline T4 & Pengguna dapat mengunduh format surat \\
\hline T5 & Pengguna dapat mengisi formulir pengajuan \\
\hline T6 & Pengguna dapat mengunggah berkas persyaratan \\
\hline T7 & Pengguna dapat melakukan konfirmasi data \\
\hline T8 & $\begin{array}{l}\text { Pengguna dapat menyimpan data yang sudah } \\
\text { dimasukan }\end{array}$ \\
\hline T9 & Pengguna dapat melihat status dari proses pengajuan \\
\hline T10 & $\begin{array}{l}\text { Pengguna dapat melihat dokumen yang sudah } \\
\text { diunggah }\end{array}$ \\
\hline T11 & Pengguna dapat melihat data yang sudah diunggah \\
\hline T12 & Pengguna dapat berinteraksi dengan pengembang \\
\hline T13 & Pengguna mendapat notifikasi aktifitas \\
\hline T14 & $\begin{array}{l}\text { Pengguna dapat melihat petunjuk penggunaan } \\
\text { aplikasi }\end{array}$ \\
\hline
\end{tabular}

\subsubsection{Identifikasi Lingkungan Sistem}

Pada tahap ini akan dijelaskan tentang spesifikasi perangkat keras, perangkat lunak dan kelengkapan lainnya yang dibutuhkan agar pengguna dapat menggunakan aplikasi sistem informasi pengajuan.

Tabel 2. Karakteristik Sistem

\begin{tabular}{|l|l|l|}
\hline No & \multicolumn{2}{|c|}{ Karakteristik Sistem } \\
\hline 1. & Hardware & $\begin{array}{l}\text { Smartphone } \text { dengan memori minimal sebesar } \\
1 \text { Gb }\end{array}$ \\
\hline 2. & Software & Aplikasi Sistem Informasi Pengajuan E-KTP \\
\hline 3. & Kelengkapan lainnya & Menggunakan koneksi internet \\
\hline
\end{tabular}




\subsection{Identifikasi Kebutuhan Pengguna}

Dari beberapa pertanyaan yang sudah diberikan melalui kuesioner, maka didapat beberapa jawaban dari 30 responden untuk mendapatkan daftar kesimpulan fitur yaitu:

1. Pengguna menyukai aplikasi mobile dengan proses daftar yang mudah

2. Pengguna menyukai adanya informasi yang lengkap dan mudah dimengerti mengenai syarat yang dibutuhkan guna mengajukan pembuatan KTP Elektronik

3. Pengguna menyukai jika aplikasi menggunakan layout grid pada tampilan halaman utama agar pengguna dapat dengan mudah mengakses fitur-fitur utama pada aplikasi

4. Pengguna menyukai aplikasi yang menyediakan menu laporan harian sehingga pengguna dapat memantau langsung proses pengajuan yang sudah dilakukan.

5. Pengguna menyukai aplikasi menggunakan bahasa yang friendly sehingga dapat dimengerti dengan mudah.

6. Pengguna menginginkan halaman konfirmasi agar pengguna dapat memeriksa kembali data yang akan diunggah.

7. Pengguna menginginkan adanya fitur live chat sehingga pengguna dapat berinteraksi langsung dengan penyedia layanan jika terdapat kendala dalam menjalankan aplikasi.

\subsection{Merancang Desain Solusi}

\subsubsection{Rancangan Arsitektur Informasi}

Rancangan arsitektur informasi pada aplikasi sistem informasi pengajuan E-KTP dibuat dalam bentuk sitemap. Rancangan arsitektur informasi dapat dilihat pada Gambar 3.

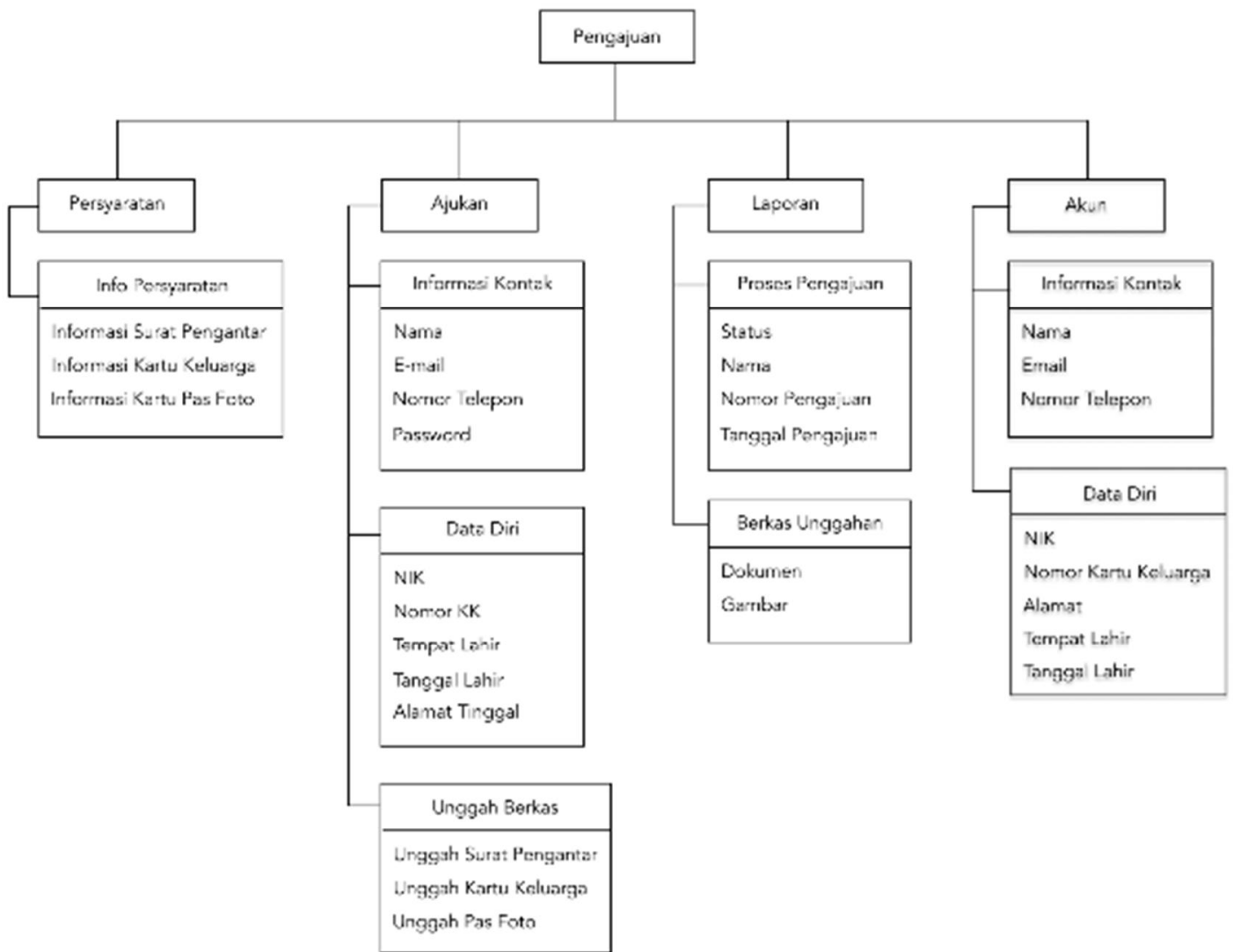

Gambar 3 Arsitektur Informasi 


\subsubsection{Rancangan Desain Solusi}

Pada tahapan ini,terdapat wireframe yang menjadi tahapan awal dari rancangan sistem yang sedang dibuat. Wireframe merupakan rancangan sistem sederhana yang belum diberikan sentuhan warna yang dijadikan acuan terhadap rancangan desain awal. Wireframe merupakan sebuah kerangka dari halaman aplikasi yang akan dirancang menjadi high-fidelty prototype dengan tujuan untuk memudahkan pengembangan aplikasi saat dibutuhkan perubahan. Berikut contoh wireframe halaman utama.

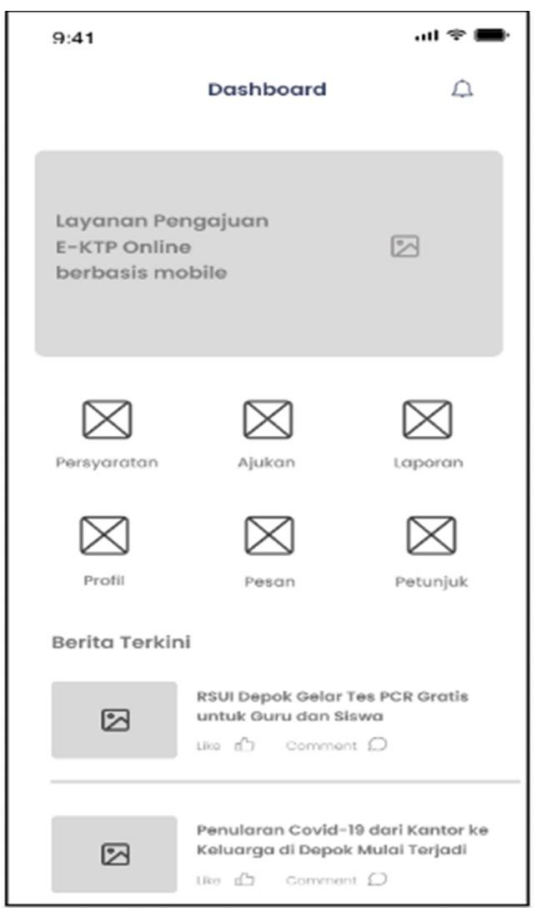

Gambar 4 Wireframe Halaman Utama

Berdasarkan hasil dari tampilan wireframe yang dibuat, maka tahap selanjutnya adalah pembuatan user-flow untuk dapat menggambarkan alur penggunaan sistem aplikasi. Berikut adalah user-flow pada sistem informasi pengajuan pembuatan E-KTP.

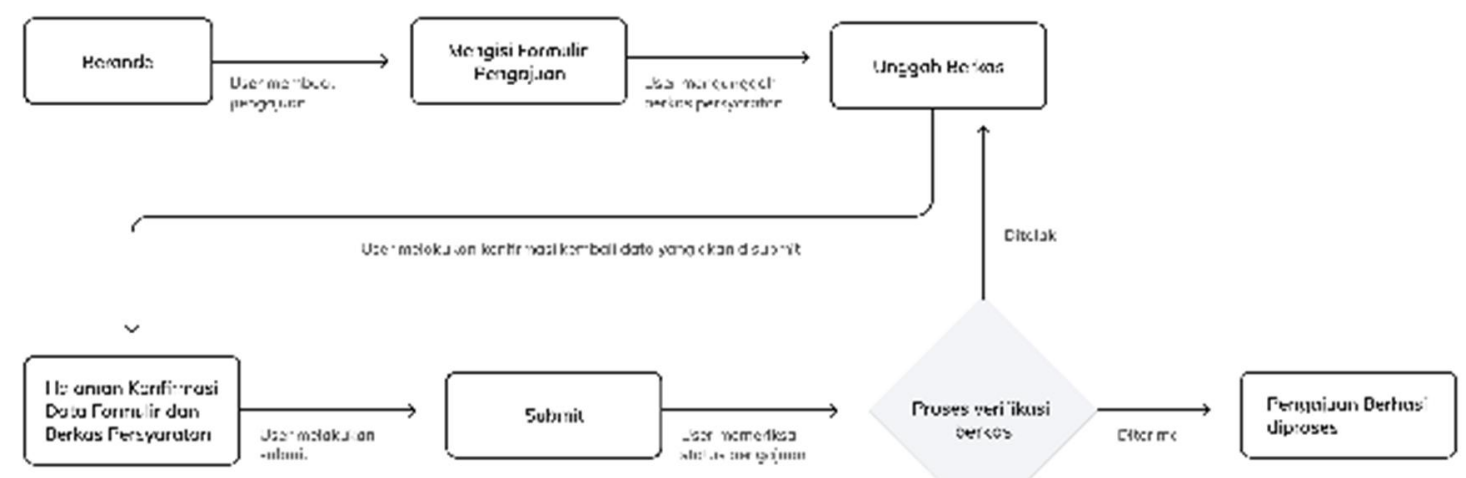

Gambar 5 User-flow Sistem Aplikasi

Sarfina, et.,al (Perancangan User Experience Aplikasi Pengajuan E-KTP Menggunakan Metode UCD Pada Kelurahan Tanah Baru) 


\subsubsection{Mockup}

Pada tahap ini merupakan tahapan pembuatan desain akhir, dimana rancangan aplikasi sudah diberikan sentuhan warna, font, ikon dan juga logo yang berguna untuk memperjelas gambaran aplikasi kepada pengguna. Mockup adalah hasil akhir rancangan yang berisi informasi yang sudah dilengkapi bentuk komponen dengan tingkat presisi yang tinggi. Pembuatan mockup pada rancangan sistem aplikasi, digunakan tools Figma karena tools ini memiliki fitur-fitur yang dibutuhkan dalam membangun rancangan sistem aplikasi. Berikut adalah mockup halaman utama aplikasi.

\subsubsection{Prototype}

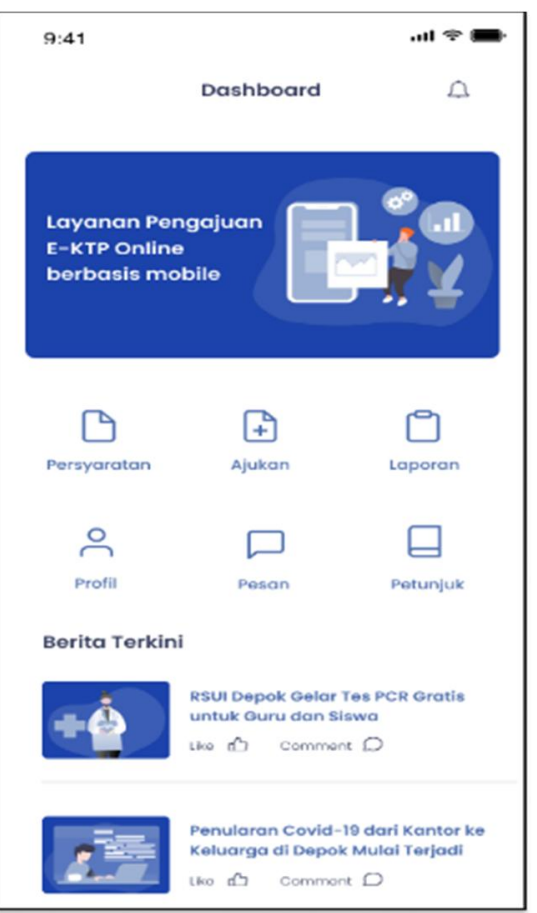

Gambar 6 Mockup Halaman Utama

Prototype adalah proses pembuatan desain dalam bentuk high-fidelty yang dapat dijadikan media komunikasi antara pengguna dengan sistem. Pembuatan prototype berdasarkan dari hasil validasi rancangan low-fidelty dan user-flow. Prototype dibangun dengan tujuan untuk memudahkan pengembang rancangan untuk menganalisa masalah, ide dan pengalaman pengguna pada saat berinteraksi dengan aplikasi. Dalam perancangan prototype sistem informasi pengajuan, menggunakan tools Figma karena pada tools tersebut, rancangan prototype akan dengan mudah dibangun.

\subsection{Evaluasi Desain}

Tahap evaluasi merupakan tahapan terakhir dalam metode UCD. Pengujian dilakukan pada 30 responden sesuai dengan target responden sebelumnya. Pengujian dilakukan dengan metode usability yang menekankan pada tiga aspek, yaitu user success rate untuk menghitung nilai dari aspek learnability, time based efficiency untuk mengetahui nilai dari aspek efisiensi dan menggunakan metode system usability scale untuk menghitung nilai dari aspek kepuasan.

\subsubsection{Learnability}

Pengujian aspek learnability digunakan untuk mengukur tingkat kemudahan aplikasi. Dalam pengujian ini dilakukan perhitungan data dengan persamaan user success rate. Success 
rate adalah presentase dari total tugas yang berhasil dikerjakan oleh pengguna [11]. Pengujian dilakukan dengan menggunakan persamaan user success rate untuk dapat melihat tingkat kemudahan pengguna untuk dalam menjalani sistem aplikasi.

$$
\begin{gathered}
\text { Success rate }=\frac{\text { Success Task }+(\text { partial success } \times 0,5)}{\text { Total Task }} \times 100 \% \text { (1) } \\
=\frac{6}{6} \times 100 \% \\
=100 \%
\end{gathered}
$$

Berdasarkan perhitungan success rate yang telah dilakukan menghasilkan nilai $100 \%$, maka , dapat diperoleh kesimpulan bahwa seluruh pengguna dapat mempelajari sistem aplikasi pengajuan E-KTP dengan mudah.

\subsubsection{Efficiency}

Aspek efficiency merupakan aspek yang mengukur tingkat performa aplikasi. Pada pengujian ini, dilakukan perhitungan berdasarkan waktu tempuh yang dibutuhkan responden dalam menjalankan task scenario yang diberikan. Berikut contoh hasil dari pengujian terhadap responden yang dijelaskan pada tabel 4.

Pada tabel 4, merupakan data hasil perhitungan nilai efisiensi berdasarkan time-based yang didapatkan pada setiap task yang diselesaikan responden dengan menggunakan rumus perhitungan

Lalu kemudian hasil yang didapatkan dari time-based setiap responden maka akan dilakukan perhitungan time-based keseluruhan dengan menggunakan rumus perhitungan:

Dimana,

$$
\frac{\sum_{j=1}^{R} \sum_{i=1}^{N} \frac{n_{i j}}{t_{i j}}}{N R}
$$

$\mathrm{N}=$ Total Tugas

$\mathrm{R}=$ Total Responden

$\mathrm{Nij}=$ Hasil dari keberhasilan pengguna saat menyelesaikan tugas. Jika berhasil maka, $\mathrm{Nij}=1$

\begin{tabular}{|c|c|c|c|c|c|c|c|}
\hline Responden & T1 & $\mathrm{T} 2$ & T3 & $\mathrm{T} 4$ & T5 & T6 & Jumlah \\
\hline R1 & 22.73 & 18.65 & 64.13 & 86.86 & 12.45 & 38.63 & 0.230928 \\
\hline R2 & 27.07 & 74.16 & 67.57 & 84.88 & 10.45 & 59.06 & 0.189632 \\
\hline R3 & 7.73 & 53.47 & 35.81 & 66.82 & 8.78 & 51.06 & 0.324439 \\
\hline $\mathrm{R} 4$ & 11.62 & 25.24 & 19.93 & 50.84 & 36.6 & 20.84 & 0.27083 \\
\hline R5 & 7.05 & 13.81 & 28.63 & 61.76 & 9.95 & 14.36 & 0.435516 \\
\hline R6 & 23.56 & 78.3 & 65.96 & 129.53 & 27.44 & 28.4 & 0.149752 \\
\hline R7 & 6.24 & 50.51 & 28.48 & 14.63 & 18.67 & 41.22 & 0.361341 \\
\hline R8 & 9.48 & 9.66 & 54.78 & 57.47 & 5.57 & 13.51 & 0.498213 \\
\hline R9 & 14.16 & 120.75 & 40.1 & 49.87 & 7.69 & 12.56 & 0.33355 \\
\hline R10 & 38.0 & 65.01 & 27.03 & 69.1 & 8.79 & 10.43 & 0.302746 \\
\hline \multicolumn{8}{|c|}{ Total Efisiensi } \\
\hline
\end{tabular}
dan jika gagal, maka $\mathrm{Nij}=0$

Tij = Waktu tempuh yang dibutuhkan pengguna untuk menuntaskan setiap tugas.

Tabel 3 Hasil Perhitungan Time Based Efficiency

Keterangan: $\mathrm{R}=$ Responden, $\mathrm{T}=$ Kode Tugas 
Berdasarkan hasil perhitungan tersebut, diperoleh hasil time-based dari setiap task yaitu: 0.085489

\subsubsection{Satisfaction}

Pada proses pengujian aspek kepuasan menggunakan system usability scale, dilakukan pembagian kuesioner kepada responden yang sudah melakukan task-scenario yang diberikan. Kuesioner tersebut terdiri dari 10 pertanyaan. Setiap pertanyaan memiliki 5 pilihan jawaban. Para responden harus menjawab berdasarkan pada tingkat persetujuan terhadap setiap pertanyaan yang diberikan. Hasil pengumpulan data dari responden dapat dilihat pada Tabel 3.

Tabel 4 Hasil Kuisioner SUS

\begin{tabular}{|c|c|c|c|c|c|c|c|c|c|c|}
\hline Responden & Q1 & Q2 & Q3 & Q4 & Q5 & Q6 & Q7 & Q8 & Q9 & Q10 \\
\hline R1 & 4 & 1 & 5 & 3 & 5 & 2 & 5 & 2 & 5 & 5 \\
\hline R2 & 4 & 1 & 5 & 1 & 5 & 1 & 5 & 1 & 5 & 1 \\
\hline R3 & 5 & 2 & 4 & 1 & 5 & 2 & 4 & 1 & 3 & 1 \\
\hline R4 & 5 & 2 & 5 & 1 & 4 & 2 & 5 & 2 & 4 & 3 \\
\hline R5 & 4 & 2 & 5 & 2 & 5 & 1 & 5 & 1 & 5 & 2 \\
\hline R6 & 4 & 2 & 4 & 3 & 4 & 3 & 4 & 2 & 4 & 4 \\
\hline R7 & 5 & 2 & 4 & 2 & 4 & 3 & 4 & 2 & 4 & 2 \\
\hline R8 & 5 & 1 & 5 & 5 & 5 & 1 & 5 & 1 & 4 & 2 \\
\hline R9 & 4 & 1 & 5 & 1 & 5 & 1 & 5 & 1 & 5 & 1 \\
\hline R10 & 3 & 1 & 5 & 1 & 5 & 1 & 5 & 1 & 5 & 1 \\
\hline
\end{tabular}

Keterangan: $\mathrm{R}=$ Responden, $\mathrm{Q}=$ Question

Setelah mengumpulkan data dari responden,kemudian data dihitung untuk mendapatkan nilai kepuasan. Perhitungan skor SUS dilakukan dengan aturan perhitungan sebagai berikut:

1. Perhitungan terhadap pertanyaan bernilai positif yaitu pada nomor $1,3,5,7$ dan 9 menggunakan rumus ( $\mathrm{x}-1)$, dimana, $\mathrm{x}$ merupakan nilai skor yang diberikan oleh responden

2. Perhitungan terhadap pertanyaan bernilai positif yaitu pada nomor $2,4,6,8$ dan 10 menggunakan rumus (5-x), dimana, $x$ merupakan nilai skor yang diberikan oleh responden

3. Untuk dapat memperoleh skor SUS, dengan cara menjumlahkan pertanyaan positif dan negatif yang kemudian dikalikan dengan 2,5.

Terdapat hasil dari perhitungan score SUS yang dijabarkan pada Tabel 4.

Tabel 5 Hasil Perhitungan Kuisioner SUS

\begin{tabular}{|c|c|c|c|c|c|c|c|c|c|c|c|}
\hline Responden & Q1 & Q2 & Q3 & Q4 & Q5 & Q6 & Q7 & Q8 & Q9 & Q10 & Jumlah \\
\hline R1 & 3 & 4 & 4 & 3 & 4 & 3 & 4 & 3 & 4 & 0 & 31 \\
\hline R2 & 3 & 4 & 4 & 4 & 4 & 4 & 4 & 4 & 4 & 4 & 39 \\
\hline R3 & 4 & 3 & 3 & 4 & 4 & 3 & 3 & 4 & 2 & 4 & 34 \\
\hline R4 & 4 & 3 & 4 & 4 & 3 & 3 & 4 & 3 & 3 & 2 & 33 \\
\hline R5 & 3 & 3 & 4 & 3 & 4 & 4 & 4 & 4 & 4 & 3 & 36 \\
\hline R6 & 3 & 3 & 3 & 2 & 3 & 2 & 3 & 3 & 3 & 1 & 27 \\
\hline R7 & 4 & 3 & 3 & 3 & 3 & 2 & 3 & 3 & 3 & 3 & 30 \\
\hline R8 & 4 & 4 & 4 & 0 & 4 & 4 & 4 & 4 & 3 & 3 & 34 \\
\hline R9 & 3 & 4 & 4 & 4 & 4 & 4 & 4 & 4 & 4 & 4 & 39 \\
\hline R10 & 2 & 4 & 4 & 4 & 4 & 4 & 4 & 4 & 4 & 38 \\
\hline \multicolumn{19}{|c|}{} \\
\hline
\end{tabular}

Keterangan: $\mathrm{R}=$ Responden, $\mathrm{Q}=$ Question 
Hasil dari perhitungan skor SUS terhadap responden, diperoleh nilai skor rata-rata sebesar 86. Hasil ini menunjukan bahwa tingkat kepuasan pengguna pada sistem aplikasi pengajuan E-KTP layak mendapat nilai B dengan adjective rating tergolong Excellent.

Tabel 6 Skor SUS

\begin{tabular}{|l|c|l|}
\hline SUS Score & Grade & Adjective Rating \\
\hline$>80,3$ & A & Excellent \\
\hline $68-80,3$ & B & Good \\
\hline 68 & C & Okay \\
\hline $51-68$ & D & Poor \\
\hline$<51$ & E & Awful \\
\hline
\end{tabular}

\section{KESIMPULAN}

Penelitian ini bertujuan untuk membangun sebuah rancangan sistem aplikasi dengan tingkat usability yang tinggi dan berfokus kepada kebutuhan pengguna. Berdasarkan hasil analisis dan penelitian yang telah dilakukan maka didapat kesimpulan sebagai berikut:

1. Pada tahap identifikasi konteks pengguna diperoleh hasil berupa tugas dan fitur yang dibutuhkan oleh pengguna. Hasil identifikasi yang diperoleh digunakan sebagai acuan untuk membangun rancangan sistem aplikasi yang sesuai dengan kebutuhan pengguna.

2. Hasil yang diperoleh dari tahapan perancangan desain solusi berupa rancangan wireframe dan kemudian pembuatan user-flow yang sesuai dengan alur wireframe yang sudah dibuat.

3. Berdasarkan pengujian usability yang menekankan 3 aspek. Yaitu aspek learnability, efficiency dan satisfaction didapatkan hasil yang memenuhi penilaian pada masing-masing pengujian. Sesuai dengan hasil yang diperoleh, maka dapat dinyatakan bahwa tingkat kepuasan pengguna dapat diterima.

\section{DAFTAR PUSTAKA}

[1] M. Ikhsan and P. Sukmasetya. 2020, Perancangan User Interface Aplikasi Central Islam Berbasis Mobile Application Dengan Metode User Centered Design (UCD), Seri Pros. Semin. ..., pp. 97-103, [Online]. Available: http://prosiding.senadi.upy.ac.id/index.php/senadi/article/view/135.

[2] I. Purnama. 2019, Perancangan Kamus Muslim Berbasis Smartphone Android Dengan Metode User Centered Design $(U c d)$, J. Inform., Vol. 5, No. 3, pp. 1-14, doi: 10.36987/informatika.v5i3.730.

[3] Z. Zhao and C. Balagué. 2014, A Design Framework of Branded Mobile Applications, MobileHCI 2014 - Proc. 16th ACM Int. Conf. Human-Computer Interact. with Mob. Devices Serv., pp. 507-512, doi: 10.1145/2628363.2634224.

[4] S. Rajeshkumar, R. Omar, and M. Mahmud. 2013, Taxonomies of User Experience (UX) Evaluation Methods, Int. Conf. Res. Innov. Inf. Syst. ICRIIS, Vol. pp. 533-538, 2013, doi: 10.1109/ICRIIS.2013.6716765. 
[5] P. Sukmasetya, H. B. Santoso, and D. I. Sensuse. 2018, Current E-Government Public Service on User Experience Perspective in Indonesia, 2018 Int. Conf. Inf. Technol. Syst. Innov. ICITSI 2018 - Proc., pp. 159-164, doi: 10.1109/ICITSI.2018.8695962.

[6] 2006, International Organization for Standardization, Ergonomics of HumanSystem Interaction - Part 210: Human-Centred Design for Interactive Systems," I, vol. 2006, p. 13.

[7] E. Ali. 2016, SATIN - Sains dan Teknologi Informasi Metode User Centered Design ( UCD ) Dalam Membangun Aplikasi Layanan, Sains dan Teknol. Inf., Vol. 2, No. 2, pp. 1-6, [Online]. Available: http://jurnal.stmik-amikriau.ac.id/index.php/satin/article/view/177/pdf.

[8] E. L. C. Law, V. Roto, M. Hassenzahl, A. P. O. S. Vermeeren, and J. Kort. 2009, Understanding, Scoping and Defining User Experience: A Survey Approach, Conf. Hum. Factors Comput. Syst. - Proc., no. June 2014, pp. 719-728, doi: $10.1145 / 1518701.1518813$.

[9] Gelinas, Ulric, Oram, Alan, Wiggins, and William. 1990, Accounting Information System, pp. 17-30.

[10] I. S. Yatana Saputri, M. Fadhli, and I. Surya. 2017, Penerapan Metode UCD (User Centered Design) pada E-Commerce Putri Intan Shop Berbasis Web, J. Nas. Teknol. dan Sist. Inf., vol. 3, no. 2, pp. 269-278, doi: 10.25077/teknosi.v3i2.2017.269-278.

[11] N. Alfiqie, M., Aknuranda, I. and Wardani. 2018, Evaluasi Usability pada Aplikasi UBER Menggunakan Pengujian Usability, J. Pengemb. Teknol. Inf. dan Ilmu Komput., vol. 2, no. 9, pp. 2599-2606, [Online]. Available: http://j-ptiik.ub.ac.id/index.php/jptiik/article/view/2367. 